(REVIEW ARTICLE)

\title{
Diagnosis of carpal tunnel syndrome in perspective of clinical features, neurophysiological studies and high resolution ultrasound
}

\author{
Aziz Nusrat* \\ Department of Physiology, Faculty of Medicine, Umm Al-Qura University, Makkah, Kingdom of Saudi Arabia.
}

Publication history: Received on 02 June 2020; revised on 12 June 2020; accepted on 14 June 2020

Article DOI: https://doi.org/10.30574/wjarr.2020.6.3.0182

\begin{abstract}
Carpal tunnel syndrome (CTS) is compression of median nerve during its course through the carpal tunnel in the hand. CTS is the most common mononeuropathy diagnosed in neurological clinics. CTS can cause pain, psychological distress, decreased performance at work, absentia from work and financial loss. The diagnosis is mainly based on high degree of clinical suspicion with positive clinical symptoms and signs and must be confirmed with either neurophysiological testing or high resolution ultrasonography. Neurophysiological studies had been the gold standard in diagnosis and grading CTS and for excluding it from other neuromuscular disorder. High resolution ultrasound is being increasingly utilized to diagnose CTS as it can show the pathology of CTS such as swelling and inflammation of median nerve and bowing of flexor retinaculum indicating compressive median neuropathy at the carpal tunnel. It is noninvasive, painless and cheaper but the measurements are operator dependent. Neurophysiological studies have well defined criteria for grading. The use of combined ultrasound and neurophysiological study show greater sensitivity and specificity than the individual procedures and can provide greater clarity to avoid false positive and false negative results. High resolution ultrasonography can help in evaluation of persistence of symptoms even after surgical release and to detect anatomical variations. Early diagnosis and grading is critical in following the appropriate treatment strategy. Clinical features, neurophysiological studies and ultrasound are valuable tools in the identification and assessment of CTS whenever each is used individually or as complementary to each other.
\end{abstract}

Keywords: Carpal Tunnel Syndrome; Clinical Features; Neurophysiological Study; Ultrasound

\section{Introduction}

Neurological abnormality in any condition provides a challenge for our normal day to day activities. Even the mildest of neurological affliction makes a person unable to perform to his or her fullest capacity causing depression, disability, dependency, lack of ability to do skillful work, absentia from work, and may ultimately develop desolate life with a considerable financial loss on the individual and the society. Diagnosing the disease early in its course and identifying the factors causing it may greatly help in its prevention and produce better treatment outcome. A major component of these neurological disorders is entrapment mononeuropathies involving a single nerve entrapped or compressed along its anatomical pathway. The most common entrapment neuropathy is Carpal tunnel syndrome (CTS) due to compression of median nerve in its anatomical course at the wrist. The estimated prevalence of clinically and electrophysiological confirmed CTS in the general population is found to be $2.7 \%$ [1] and an incidence of 491 and 258 per 100,000 person-years for women and men respectively[2] with high preponderance in females. CTS is observed more in working population with a prevalence of $7.8 \%$ in United States [3]. The cost of treatment by surgical release operation for CTS can be anywhere from $\$ 2149$ to $\$ 9927$ per patient, accounting to $\$ 2$ billion for 500000 release operations every year in United States alone [4,5]. Cumulated loss of earnings over a period of 6 years was found to be $\$ 45,000-\$ 89,000$ per CTS patient in a study on United States claimants of workers compensation insurance [6]. This highlights the importance of an in-depth analysis on causative factors, prevention, early diagnosis and treatment so as to minimize the misery of pain, the disability, permanent damage to nerve and the financial burden. Furthermore it

\footnotetext{
* Corresponding author: Aziz Nusrat
} 
effects the outcome of treatment as has been observed by surgical treatment showed improvement in $100 \%$ of mild CTS cases compared to $84 \%$ in cases of moderate CTS [7]

Carpal tunnel is an osteofibrous canal formed by the flexor retinaculum or transverse carpal ligament attached to the arch of the carpal bones at the hamate and pisiform medially and scaphoid and trapezoid carpal bones at the lateral or radial aspect of wrist between the carpal bones and the flexor retinaculum on the palmar aspect of hand just distal to the wrist. The transverse carpal ligament is $1-3 \mathrm{~mm}$ in thickness and $3-5 \mathrm{~cm}$ wide. It allows the passage of 9 tendons that is 4 tendons of flexor digitorum profundus, 4 tendons of flexor digitorum superficialis and tendon of flexor pollicis longus [8] and the tendon of flexor carpi radialis traverse through a separate fascial compartment between the two laminae of transverse carpal ligament. The median nerve while passing through the forearm supplies the muscles of anterior compartment except the flexor carpi ulnaris and the medial part of flexor digitorum profundus. It passes between the tendons of flexor digitorum superficialis and flexor digitorum profundus to lie superficially at the wrist. Just proximal to the distal wrist crease it enters the carpal tunnel lying superficial to the tendons of flexor pollicis longus and flexor digitorum superficialis on the palmar aspect of hand. Studies reveal a wrist ratio (ratio between the wrist depth at distal flexor wrist crease to the wrist width measured at distal crease) higher than 0.69 or a more square shaped wrist increases the likelihood of CTS by3- $8 \% .[9,10,11]$

Before entering the carpal tunnel it gives of the palmar cutaneous branch for sensory supply to skin over the surface of the thenar eminence. Inside the carpal tunnel, the digital cutaneous branch and the recurrent branch of median nerve arise just distal to the carpal tunnel. The digital cutaneous branch supplies the skin over the lateral 3and half fingers on the palmar surface and the similar digits upto the distal to the proximal interphalengeal joint on the dorsal surface of hand which relate to the distribution of sensory symptoms of carpal tunnel syndrome. It also supplies the first two lumbricals going to the 2 and 3 digits. The recurrent branch of median nerve supplies the muscles of the thenar eminence- opponens pollicis, abductor pollicis brevis, and superficial part of flexor pollicis brevis. Carpal tunnel syndrome can cause weakness in these muscles leading to hand weakness, hand clumsiness and impaired pinch precision [12,13]. It has observed that median motor function starts getting affected in the mild stage of CTS itself [13] as opposed popular belief that sensory only is affected in early stages.

Carpal tunnel syndrome occurs due to compression of median nerve as it passes under the flexor retinaculum through the carpal tunnel. The pressure in carpal tunnel in CTS patients have been found to be higher than controls specially in the midsection of the tunnel which increases several fold with dynamic changes, more with extreme flexion than extension of wrist $[15,16]$ The carpal tunnel pressure as well as the median intraneural pressure decreases significantly with release operation of transverse flexor retinaculum $[17,18,19]$ with alleviation of symptoms in most of the cases unless permanent damage to the nerve has occurred.

Most of the cases are idiopathic with no true identifiable cause but it has been established that there are certain risk factors which increases the likelihood of CTS such as increase in repetitive movement of hand at the wrist e.g.: assembly line workers, increased exposure to vibrations at the wrist as an occupational hazard, hormonal abnormalities like hypothyroidism, acromegaly, in use of aromatase inhibitors in hormone dependent breast cancer treatment. [20], collagen disorders like rheumatoid arthritis, metabolic disorders like diabetes mellitus and chronic renal insufficiency, fluid retention as in pregnancy, fractures or trauma to wrist, osteoarthritis of wrist [21] and obesity

The peak age of CTS was found to be 45-60yrs [24]. The compression of the median nerve occurs mostly as a result of hypertrophy or edema of synovial sheaths of flexor tendons leading to elevated carpal tunnel pressures causing increase in mechanical contact pressure between the carpal tunnel structures, producing edema of the median nerve followed by ischemic changes in the nerve with decreased perineural blood flow in mild cases, associated with loss of myelin sheath in moderate cases and in severe cases cause damage to the nerve axon itself [22, 23,24].

\section{Clinical signs and symptoms}

The clinical features (Table 1) include,

\subsection{Gender}

Females are more likely to develop CTS than males with a prevalence rate of $9.2 \%$ in females and $6 \%$ in males [25] But a study has observed when job profiles are same then the likelihood of CTS in males or females is almost equal [26] though females are more likely to present earlier with milder symptoms compared to males [27] who may seek help in more advanced severity. 


\subsection{Age}

Peak incidence of CTS was found to be between 45-60 and only 10\%were found to be below 31 years of age[28,29] in both sexes though the no. of cases were much higher in females.

\subsection{Occupation}

Prevalence in blue collar workers was double that in white collar workers [30]

\subsection{Clinical symptoms}

The clinical symptoms of CTS are 1 . Sensory symptoms pain numbness paresthesia nocturnal symptoms, 2 . Motor symptoms, 3 . Autonomic symptoms

\subsubsection{Sensory symptoms}

The sensory symptoms are first to be manifested in a case of CTS following the initial pathology of demyelination of the nerve. These include numbness, tingling, pain, decreased sensation in any or all fingers innervated by median nerve that is thumb, index finger or the middle finger. It is unlikely to be CTS if it is ring finger or little fingers which are supplied by ulnar nerve. The Katz hand diagram (Fig 1) shows a sensitivity of $80 \%$ and specificity of $90 \%$ with the classic and probable presentation of numbness, tingling pain and paresthesia [31]. Nocturnal pain, pain provoked by extreme positions of hand and repetitive movements favors CTS and history of pain getting relieved by shaking the hand that is Flick sign or changing the position of hand adds to diagnosis.

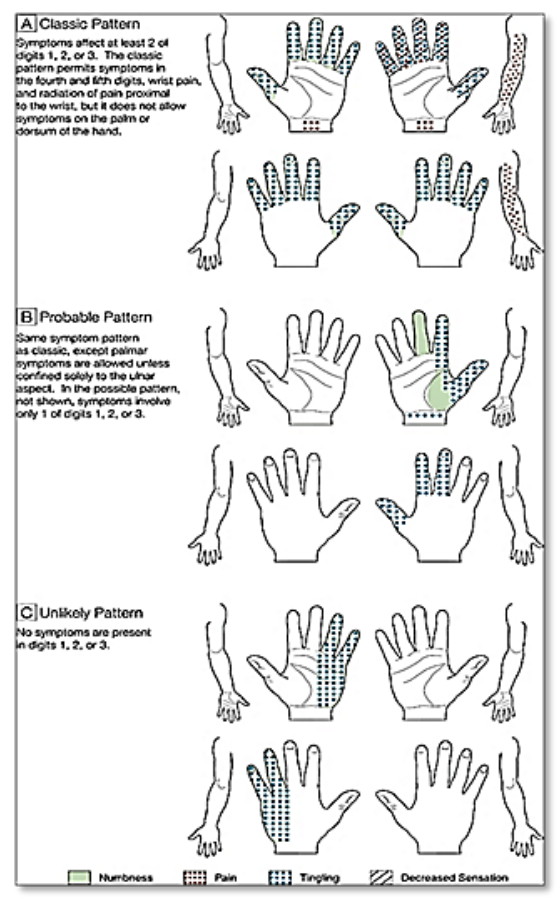

Figure 1 Katz Hand Diagram For sensory symptoms of CTS [31]

\subsubsection{Motor symptoms}

Motor symptoms include weakness and atrophy of thenar eminence that is the muscles of abductor pollicis brevis, opponens pollicis and flexor pollicis brevis observed as hand weakness and hand clumsiness may be observed in moderate to severe CTS and may also be correlated with fibrillations and fasciculation in these muscles by Electromyography (EMG). EMG is also a useful tool to exclude other neuromuscular disorders with similar presentation as CTS.

\subsubsection{Autonomic symptoms}

Autonomic symptoms like swelling color changes, sweating and skin temperature with significant alteration in sympathetic skin response have been observed to increase with increasing severity of electrophysiological findings 
observed as significant difference between median and ulnar SSR response but studies cannot give definitive clinical association with mild CTS [32, 33,34]

\subsection{Clinical tests}

For CTS have been found to have low validity and must be confirmed with electrophysiological studies [35]. Provocative tests such as

\subsubsection{Phalens test}

Ask the subject to bring the two hands together and perform extreme flexion of about for about 30 seconds. It can reproduce the symptoms

\subsubsection{Tinels percussion test}

Tap on the median nerve at the wrist reproduces symptoms.

\subsubsection{Manual carpal compression test}

Applying pressure over the carpal tunnel for about 30 seconds reproduces the symptoms.

Table 1 Clinical signs and symptoms of Carpal Tunnel Syndrome

\begin{tabular}{|c|c|}
\hline Symptoms and signs & Findings indicative of CTS \\
\hline Age & $40-60$ years \\
\hline Gender & Female $>$ males \\
\hline Risk Factors & $\begin{array}{l}\text { Obesity, Diabetes mellitus, hypothyroidism, } \\
\text { rheumatoid arthritis, Chronic Renal failure, pregnancy }\end{array}$ \\
\hline Occupation & $\begin{array}{l}\text { More in occupation involving repeated hand } \\
\text { movements or vibrations }\end{array}$ \\
\hline Sensory symptoms & $\begin{array}{l}\text { Pain } \\
\text { Paresthesia } \\
\text { Numbness } \\
\text { Classic or Probable pattern of Katz Hand Diagram } \\
\text { Flicks sign }\end{array}$ \\
\hline Motor symptoms & $\begin{array}{l}\text { Hand Clumsiness } \\
\text { Weakness of Thumb } \\
\text { Atrophy of Thenar Muscles }\end{array}$ \\
\hline Autonomic symptoms & $\begin{array}{l}\text { Swelling or Feeling of Tightness in Hand } \\
\text { Temperature change } \\
\text { Difference in skin color } \\
\text { Difference in sympathetic skin response of median to } \\
\text { ulnar nerve }\end{array}$ \\
\hline Provocative tests & $\begin{array}{l}\text { Phalen's test } \\
\text { Tinel sign } \\
\text { Manual Carpal Compression test }\end{array}$ \\
\hline
\end{tabular}

\section{Electro diagnostic testing}

Though CTS is mainly a clinical diagnosis, Electro diagnostic testing is important to confirm the diagnosis, grade its severity and rule out any other disease such as peripheral neuropathy, radiculopathy, plexopathy or any other neuromuscular disorders mimicking it. The tests performed (Table 2) are the following 


\subsection{Median sensory nerve action potential over first to fourth finger}

Antidromic conduction studies are better to use as the amplitude of response is higher than that of orthodromic technique. The $2^{\text {nd }}$ digit is most often used for sensory testing. Put the reference (red) electrode over the distal interphalengeal joint and the active (black) electrode $3 \mathrm{~cm}$ proximal to the red electrode on the 2 nd digits. Stimulate the median nerve at the wrist between $13 \mathrm{~cm}$ proximal to the active (black) electrode. A response showing onset distal latency of less than $3.5 \mathrm{~m}$ and amplitude of $>20 \mathrm{mV}$ is taken as normal. If the response is abnormal, compare it with sensory response of either ulnar or radial nerve of the same limb. An abnormal response of other nerves excludes CTS. Mild CTS causes delayed peak latency beyond 3.7ms. Moderate to severe CTS is shows prolonged distal latency along with decreased amplitude which may be associated with increased median motor nerve latency. Severe CTS may show absent sensory response with increased latency and decreased amplitude of median motor nerve.

\subsection{Median compound muscle nerve action potential over the Abductor pollicis brevis muscle}

Put the active electrode (black) on the belly of the APB muscle and the reference electrode on the tendon (red). Stimulate $8 \mathrm{cms}$ proximal to active electrode over the median nerve at the wrist. A distal latency of $<4.4 \mathrm{~ms}$ and amplitude of $>4 \mathrm{mV}$ is taken as normal.

\subsection{Comparison between sensory latency median and ulnar nerves recorded from $2^{\text {nd }}$ and $5^{\text {th }}$ digit respectively}

Keep the reference and active electrodes over the $2^{\text {nd }}$ digit and stimulate $14 \mathrm{~cm}$ proximal to active electrode over the wrist. Compare its latency with that of ulnar nerve stimulated at the wrist with recording electrodes at the $5^{\text {th }}$ digit. A difference of more than $0.5 \mathrm{~ms}$ between their peak latencies indicates CTS.

\subsection{Comparative test with ulnar nerve over ring finger}

Place the recording electrodes on the ring finger on proximal and distal interphalangeal joints $3 \mathrm{~cm}$ apart and stimulate the median nerve $13 \mathrm{~cm}$ proximal to active electrode at the wrist and the ulnar nerve $13 \mathrm{~cm}$ proximal over ulnar nerve at wrist. Normal value is $0.4 \mathrm{~m}$ or less. An increase in latency of median nerve by $0.5 \mathrm{~ms}$ or more than ulnar latency indicates CTS.

\subsection{Comparative test with radial nerve over the thumb}

Place the recording electrodes over the thumb and stimulate the median nerve and the radial nerve over their respective location at the wrist $10 \mathrm{~cm}$ proximal to the active electrode. Normal value is $0.5 \mathrm{~m}$ or less. An increased in median wrist distal latency by $>0.5 \mathrm{~ms}$ than that of radial nerve indicates CTS.

\subsection{Comparison between lumbrical and introssie motor response by stimulating median and ulnar nerves respectively}

The red electrode is placed over the proximal interphalengeal joint, the active (black) electrode between the midpoints of $2^{\text {nd }}$ and $3^{\text {rd }}$ metacarpals with the ground (green) electrode on the dorsum. Stimulate the motor median nerve and the motor ulnar nerve at their respective wrist locations at a distance of $10 \mathrm{~cm}$ from the active electrode. CMAP are recorded from $2^{\text {nd }}$ second lumbrical for median nerve and interosseous for ulnar nerve muscles. A difference of $>0.4 \mathrm{~ms}$ is taken as CTS [36]. Even in cases of severe CTS with absent sensory and motor response this technique can be used to localize the lesion [37].

\subsection{Median-ulnar palmar mixed comparison orthodromic study}

Place the recording electrodes over the median and ulnar nerves at the wrist at their respective locations. Stimulate at the palm between midpoints of $2^{\text {nd }}$ and $3^{\text {rd }}$ metacarpals for median nerve and midpoints between $4^{\text {th }}$ and $5^{\text {th }}$ metacarpals for ulnar nerve, both $8 \mathrm{~cm}$ distal to the recording electrodes.Normal value $0.3 \mathrm{~ms}$ and less. A difference of latency of $0.4 \mathrm{~ms}$ or more $[38,39]$ indicates CTS.

\subsection{Comparison of distal latency between Palm and wrist stimulation}

The electrodes are placed over $2^{\text {nd }}$ digit for antidromic median sensory SNAP recording and stimulation is $7 \mathrm{~cm}$ proximal over the palm and $14 \mathrm{~cm}$ proximal to active electrode at the wrist over the median nerve. Proximal amplitude less than $50 \%$ of distal response amplitude indicates conduction block and neuropraxia at the carpal tunnel [38]. 


\subsection{Inching technique}

The electrodes are placed over the second digit for antidromic SNAP and 7-8 segmental stimulations are done starting from $10 \mathrm{cms}$ proximal to the active electrode at the wrist. Each consecutive stimulation is done with a decrement of 1 $\mathrm{cm}$ towards the active electrode. An increase in distal latency of $>0.5 \mathrm{~ms}$ across the carpal tunnel is diagnostic of CTS. [41] It also distinguishes it from diabetic neuropathy [42]. Segmental tests over the course of median nerve: the segmental studies are more sensitive than the comparative tests [41] for CTS.

Table 2 Nerve Conduction Studies and EMG In Carpal Tunnel Syndrome

\begin{tabular}{|c|c|c|}
\hline Electrodiagnostic Test & Electrodiagnostic test and Site of recording & Response indicative of CTS \\
\hline $\begin{array}{l}\text { Median sensory Nerve } \\
\text { Action Potential(SNAP) }\end{array}$ & Over 1st to 4th finger & $\begin{array}{l}\text { Onset latency }>3.5 \mathrm{msand} \\
\text { Amplitude }<20 \mathrm{mV} \text { with normal } \\
\text { response of other nerves of the } \\
\text { same hand }\end{array}$ \\
\hline $\begin{array}{l}\text { Median Compound } \\
\text { Muscle action Potential } \\
\text { (CMAP) }\end{array}$ & Over Abductor Pollicis Longus & $\begin{array}{l}\text { Distal latency }>4.4 \mathrm{~ms} \text { and } \\
\text { Amplitude }<4 \mathrm{mV}\end{array}$ \\
\hline \multirow[t]{2}{*}{ Segmental tests } & $\begin{array}{l}\text { Comparison of amplitude of median SNAP } \\
\text { between stimulation at wrist and stimulation at } \\
\text { palm }\end{array}$ & $\begin{array}{l}\text { Proximal amplitude less than } \\
50 \% \text { of distal response amplitude }\end{array}$ \\
\hline & Inching technique & $\begin{array}{l}\text { increase in distal latency of } \\
>0.5 \mathrm{~ms} \text { across the carpal tunnel }\end{array}$ \\
\hline \multirow[t]{5}{*}{ Comparative Tests } & $\begin{array}{l}\text { Comparison between the Median SNAP at 2nd } \\
\text { digit with Ulnar SNAP at } 5 \text { th digit }\end{array}$ & $\begin{array}{l}\text { Increased latency by }>0.5 \mathrm{~ms} \text { of } \\
\text { Median than Ulnar }\end{array}$ \\
\hline & $\begin{array}{l}\text { Comparison between distal latencies of the } \\
\text { Median and Ulnar SNAP recorded over the 4th } \\
\text { digit }\end{array}$ & $\begin{array}{l}\text { Increased latency by }>0.5 \mathrm{~ms} \text { of } \\
\text { Median than Ulnar }\end{array}$ \\
\hline & $\begin{array}{l}\text { Comparison between distal latencies of the } \\
\text { Median and Radial SNAP recorded over the } 1 \text { st } \\
\text { digit }\end{array}$ & $\begin{array}{l}\text { Increased latency by }>0.5 \mathrm{~ms} \text { of } \\
\text { Median than Radial }\end{array}$ \\
\hline & $\begin{array}{l}\text { Comparison between the Lumbrical and } \\
\text { Introssei motor response }\end{array}$ & $\begin{array}{l}\text { Increased latency by }>0.5 \mathrm{~ms} \text { of } \\
\text { median lumbrical than Ulnar } \\
\text { introssei }\end{array}$ \\
\hline & $\begin{array}{l}\text { Comparison between the Median and Ulnar } \\
\text { Palmar mixed Orthodromic Study }\end{array}$ & $\begin{array}{l}\text { Increased latency by }>0.4 \mathrm{~ms} \text { of } \\
\text { median than Ulnar }\end{array}$ \\
\hline Electromyography & Of Abductor Pollicis Brevis & $\begin{array}{l}\text { Presence of Fasciculation and } \\
\text { Fibrillation }\end{array}$ \\
\hline
\end{tabular}

Neurophysiological Grading of carpal tunnel syndrome based on Blands classification [43] is given in (Table 3).

\subsection{Combined sensory index}

The combined sensory index (CSI) is sum of median-radial latency difference+ median-ulnar latency difference+ median ulnar palmar orthodromic latency difference better than considering only median sensory distal latency[44,45] in detecting CTS in early stage. A CSI of more than 1 is taken as early CTS in cases where sensory distal latency of SNAP and motor CMAP are within normal range. A comparison of distal latency between palm and wrist stimulation as a single test showed the highest likelihood ratio [46] 
Table 3 Neurophysiological Grading of carpal tunnel syndrome based on Blands classification [43]

\begin{tabular}{ll}
\hline Grade of Carpal Tunnel syndrome & Neurophysiological finding \\
\hline Grade 0 -normal & No abnormality detected neurophysiologically \\
Grade 1 - very mild & Detected in sensitive segmental and comparative \\
Grade 2 - mild & $\begin{array}{l}\text { Increased sensory latency of }>3.5 \mathrm{~ms} \text { or decreased sensory conduction } \\
\text { velocity }<40 \mathrm{~m} / \mathrm{s} \text { with normal motor response of median nerve }\end{array}$ \\
Grade 3 - moderate & $\begin{array}{l}\text { Increased sensory latency with decreased amplitude, increased motor } \\
\text { latency of }>4.5 \mathrm{~ms}\end{array}$ \\
Grade 4 - severe & Motor latency $>4.5 \mathrm{~ms}$ with absent sensory response \\
Grade 5 - very severe & Motor latency $>6.5$ ms \\
Grade 6 - extremely severe & Decreased CMAP amplitude $<0.2 \mathrm{mV}$ \\
\hline
\end{tabular}

\section{High resolution ultrasound}

High resolution Ultrasound is an easy, noninvasive, cheaper and painless procedure for confirming CTS done by an experienced and skillful radiologist. The shape, crossectional area (CSA) and echogenicity are considered. Decreased echogenicity with increased crossectional area indicates median nerve edema. A hyperechoic median nerve may be a sign of demyelination and fibrosis. A compression in carpal tunnel will show hourglass figure of median nerve with increased CSA proximally and distally and compression in the middle of flexor retinaculum. Ultrasonography is highly useful for evaluation of postoperative carpal tunnel syndrome which might show fibrosis and adhesions over the flexor retinaculum. High resolution ultrasound is used also to exclude abnormality of palmar cutaneous nerve which may be a cause of persistence of symptoms. Ultrasound studies have shown there is swelling of the nerve proximal to the carpal tunnel observed as increased proximal cross sectional area (CSA)of more than $9-11 \mathrm{~mm} 3[47,48,49]$ with CSA of $>11.4$ $\mathrm{mm} 3$ in Electrodiagnostic mild CTS[47] which may be lesser that is $>9.4 \mathrm{~mm} 3$ in clinically positive CTS with normal nerve conduction study [50]. The ultrasonographic parameters (Table 4) considered for CTS are

\subsection{Proximal cross sectional area (CSA) of median nerve}

The CSA is measured at opening or entry of median nerve into the carpal tunnel between the pisiform and the scaphoid bones. Hypoechoic median nerve with CSA equal to or more than 9-11square mm has been taken as CTS. A cut off area of $>10$ square millimeter of proximal median nerve has a sensitivity, specificity and accuracy of $85 \%, 92 \%$ and $89.3 \%$ [51].

\subsection{Distal cross sectional area and its ratio with the proximal CSA}

Measurement of median CSA distally at the exit of carpal tunnel between the trapezium and the hamate bones: An inlet to outlet ratio of 1.14 [52] or above indicates CTS.

\subsection{Ratio of median CSA at the wrist and the forearm}

Ratio of more than > 1.4 is diagnostic of CTS. A difference in CSA of more than $2.1 \pm 0.5$ square millimeter indicates CTS with a sensitivity and specificity of $99 \%$ and $100 \%[53,54]$.

\subsection{Palmar bowing of flexor retinaculum}

Palmar bowing of flexor retinaculum of more than 2 square mm outside the line connecting pisiform with scaphoid indicates likelihood of CTS. 
Table 4 Ultrasonography Criteria for Diagnosis of Carpal Tunnel Syndrome

\begin{tabular}{ll}
\hline Ultrasonographic test & Ultrasonographic Findings indicative of CTS \\
\hline $\begin{array}{l}\text { Proximal Cross Section Area (entry/inlet of carpal } \\
\text { tunnel) }\end{array}$ & $\begin{array}{l}\text { Cross sectional area (CSA) equal to or more than 9-11 } \\
\text { square mm }\end{array}$ \\
$\begin{array}{l}\text { Proximal to Distal Cross Section Area ratio (inlet to } \\
\text { outlet ratio) }\end{array}$ & $\begin{array}{l}\text { inlet to outlet CSA ratio of 1.14 or above } \\
\text { Wrist-Forearm Ratio }\end{array}$ \\
\begin{tabular}{l} 
Palmar Bowing of Flexor Retinaculum \\
\hline
\end{tabular}
\end{tabular}

\section{Conclusion}

The diagnosis of CTS is mainly clinical but the role of neurophysiological studies and ultrasound is also crucial in confirming diagnosis, grading the severity and excluding other neuromuscular conditions as the etiology. The treatment strategy and the outcome depend heavily on the severity of the disease. In the present times with increased patient awareness and physician training, most of the CTS cases diagnosed are in mild stage but the chances of false negative or false positive increase with such borderline severity. It is utmost important in diagnosing such cases with accuracy to avoid unnecessary expenditure of money and time in false positive case or delaying treatment in false negative cases causing patient suffering and monetary loss. Neurophysiological testing had been the gold standard in diagnosis of CTS. Evaluation with neurophysiological testing along with ultrasound showed sensitivity of $86 \%$ and specificity of $83 \%$ which is higher than that of neurophysiological testing or ultrasound alone[55]. CTS with grade more than very mild are easier to diagnose with confirmation of diagnosis and severity with either neurophysiological testing or ultrasound before analyzing the treatment and outcome. Very mild cases can ideally have neuro-electrophysiological testing followed by ultrasound because of its high diagnostic accuracy [56] to avoid false negative or false positive tests.

\section{Compliance with ethical standards}

\section{Acknowledgments}

All praise to Almighty for making this publication possible and his countless blessings for which I could never be able thank enough.

I would like to thank my husband Fazal Mustafa Ali Khan and my kids for their support and encouragement in fulfilling this project. I am thankful to my parents whose sincere efforts have been instrumental in making me who I am.

\section{Disclosure of conflict of interest}

The author declares that there is no conflict of interest and no funding was taken from the institution or any other funding department.

\section{References}

[1] Atroshi I. (1999). Prevalence of Carpal Tunnel Syndrome in a General Population. JAMA, 282(2), 153.

[2] Gelfman R, Melton L, Yawn B, Wollan P, Amadio P and Stevens J. (2009). Long-term trends in carpal tunnel syndrome. Neurology, 72(1), 33-41.

[3] Dale A, Harris-Adamson C, Rempel D, Gerr F, Hegmann K, Silverstein B et al. (2013). Prevalence and incidence of carpal tunnel syndrome in US working populations: pooled analysis of six prospective studies. Scandinavian Journal of Work, Environment \& Health, 39(5), 495-505.

[4] Milone M, Karim A, Klifto C and Capo J. (2017). Analysis of Expected Costs of Carpal Tunnel Syndrome Treatment Strategies. HAND, 155894471774359.

[5] Palmer DH and Hanrahan LP. (1995). Social and economic costs of carpal tunnel surgery. Instr Course Lect, 44, 167-72. 
[6] Foley M, Silverstein B and Polissar N. (2007). The economic burden of carpal tunnel syndrome: Long-term earnings of CTS claimants in Washington State. American Journal of Industrial Medicine, 50(3), 155-172.

[7] Zeidman L and Pandey D. (2017). A carpal tunnel grading system including combined sensory index-diagnosed mild cases: Relation to presenting features and outcomes. Muscle \& Nerve, 57(1), 45-48.

[8] Presazzi A, Bortolotto C, Zacchino M, Madonia L and Draghi F. (2011) Carpal tunnel: Normal anatomy, anatomical variants and ultrasound technique. Journal of Ultrasound, 14(1), 40-46.

[9] Ozcakir S, Sigirli D and Avsaroglu H. (2018). High wrist ratio is a risk factor for carpal tunnel syndrome. Clinical Anatomy, 31(5), 698-701.

[10] Shiri R. (2015). A square-shaped wrist as a predictor of carpal tunnel syndrome: A meta-analysis. Muscle \& Nerve, 52(5), 709-713.

[11] Kouyoumdjian J, Morita M, Rocha P, Miranda R and Gouveia G. (2000). Wrist and palm indexes in carpal tunnel syndrome. Arquivos de Neuro-Psiquiatria, 58(3A), 625-629.

[12] Tamburin S, Cacciatori C, Marani S and Zanette G. (2008). Pain and motor function in carpal tunnel syndrome. Journal of Neurology, 255(11), 636-1643.

[13] Li K, Evans P, Seitz W and Li Z. (2015). Carpal tunnel syndrome impairs sustained precision pinch performance. Clinical Neurophysiology, 126(1), 194-201.

[14] Seok H, Kim J, Kim Y, Park M and Kwon D. (2019). Quantitative evaluation of hand motor function using a gyrosensor in mild and moderate carpal tunnel syndrome. Muscle \& Nerve, 59(4), 465-469.

[15] Luchetti R, Schoenhuber R, Cicco G, Alfarano M, Deluca S and Landi A. (1989). Carpal-tunnel pressure. Acta Orthopaedica Scandinavica, 60(4), 397-399.

[16] Luchetti R and Schoenhuber R. (2007). Carpal Canal Pressure Measurements: Literature Review and Clinical Implications. In: Luchetti R., Amadio P. (eds) Carpal Tunnel Syndrome. Springer, Berlin, Heidelberg.

[17] Okutsu I, Ninomiya S, Hamanaka I, Kuroshima N and Inanami H. (1989). Measurement of pressure in the carpal canal before and after endoscopic management of carpal tunnel syndrome. The Journal of Bone \& Joint Surgery, 71(5), 679-683.

[18] Okutsu I, Hamanaka I, Chiyokura Y, Miyauchi Y and Sugiyama K. (2001). Intraneural Median Nerve Pressure in Carpal Tunnel Syndrome. Journal of Hand Surgery, 26(2), 155-156.

[19] Kim D, Marquardt T, Gabra J, Shen Z, Evans P, Seitz W et al. (2012). Pressure-morphology relationship of a released carpal tunnel. Journal of Orthopaedic Research, 31(4), 616-620.

[20] Nishihori T, Choi J, DiGiovanna M, Thomson J, Kohler P, McGurn J et al. (2008). Carpal Tunnel Syndrome Associated with the Use of Aromatase Inhibitors in Breast Cancer. Clinical Breast Cancer, 8(4), 362-365.

[21] Geoghegan J, Clark D, Bainbridge L, Smith C and Hubbard R. (2004). Risk Factors in Carpal Tunnel Syndrome. Journal of Hand Surgery, 29(4), 315-320.

[22] Werner R and Andary M. (2002). Carpal tunnel syndrome: pathophysiology and clinical neurophysiology. Clinical Neurophysiology, 113(9), 1373-1381.

[23] Myers RR, Heekman HM and Powell HC. (1985). Pathology Of Experimental Nerve Compression. Journal of Neuropathology and Experimental Neurology, 44(3), 347.

[24] Carpal Tunnel Syndrome [Internet]. (2019). Practice Essentials, Pathophysiology, Epidemiology.

[25] RASK M. (1979). Anterior Interosseous Nerve Entrapment. Clinical Orthopaedics and Related Research, \&NA, (142), 176-181.

[26] McDiarmid M, Oliver M, Ruser J and Gucer P. (2008). Male and Female Rate Differences in Carpal Tunnel Syndrome Injuries: Personal Attributes or Job Tasks? Environmental Research, 83(1), 23-32.

[27] Bland J. (2003). Clinical surveillance of carpal tunnel syndrome in two areas of the United Kingdom, $1991-2001$. Journal of Neurology, Neurosurgery \& Psychiatry, 74(12), 1674-1679.

[28] Ashworth NL. (2019). How does the incidence of carpal tunnel syndrome (CTS) vary by age?

[29] Wainner R, Fritz J, Irrgang J, Delitto A, Allison S and Boninger M. (2005). Development of a clinical prediction rule for the diagnosis of carpal tunnel syndrome. Archives of Physical Medicine and Rehabilitation, 86(4), 609-618. 
[30] Atroshi I. (1999). Prevalence of Carpal Tunnel Syndrome in a General Population. JAMA, 282(2), 153.

[31] Katz J and Stirrat C. (1990). A self-administered hand diagram for the diagnosis of carpal tunnel syndrome. The Journal of Hand Surgery, 15(2), 360-363.

[32] Verghese J, Galanopoulou A and Herskovitz S. (2000). Autonomic dysfunction in idiopathic carpal tunnel syndrome. Muscle \& Nerve, 23(8), 1209-1213.

[33] Sorgun M, Tugan Yildiz C and Sener H. (2018). Autonomic involvement in carpal tunnel syndrome - sympathetic skin response and skin temperature. Neurological Sciences and Neurophysiology, 35(1), 14-20.

[34] Anibal L, Faisal A, Lonni S, Jose G, Abdulrahman A and Naganand S. (2014). Association of Autonomic Symptoms in Carpal Tunnel Syndrome with Abnormalities in Sympathetic Skin Responses. Neurology, 82(10 Supplement) 4-115.

[35] De Krom M, Knipschild P, Spaans F and Kester A. (1990). Efficacy of provocative tests for diagnosis of carpal tunnel syndrome. The Lancet, 335(8686), 393-395.

[36] Stevens JC. (1997). AAEM minimonograph \#26: The electrodiagnosis of carpal tunnel syndrome. Muscle \& Nerve, 20(12), 1477-86.

[37] Lee S, Kim D, Cho H, Nam H and Park D. (2016). Diagnostic Value of the Second Lumbrical-Interosseous Distal Motor Latency Comparison Test in Severe Carpal Tunnel Syndrome. Annals of Rehabilitation Medicine, 40(1), 50.

[38] Werner R and Andary M. (2011). Electrodiagnostic evaluation of carpal tunnel syndrome. Muscle \& Nerve 44(4), 597-607.

[39] Daube JR. (1977).Percutaneous palmar median nerve stimulation for carpal tunnel syndrome. Electroencephalogr Clin Neurophysiol, 43, 139-40.

[40] Basiri K and Katirji B. (2015) Practical approach to electrodiagnosis of the carpal tunnel syndrome: A review. Advanced Biomedical Research, 4(1), 50.

[41] Sheu J, Yuan R, Chiou H, Hu C and Chen W. (2006). Segmental study of the median nerve versus comparative tests in the diagnosis of mild carpal tunnel syndrome. Clinical Neurophysiology, 117(6), 1249-1255.

[42] Hansson S. (1995). Segmental median nerve conduction measurements discriminate carpal tunnel syndrome from diabetic polyneuropathy. Muscle \& Nerve, 18(4), 445-453.

[43] Bland J. (2000). A neurophysiological grading scale for carpal tunnel syndrome. Muscle \& Nerve, 23(8), 12801283.

[44] Kouyoumdjian J, Morita M and Molina A. (2002). Usefulness of additional nerve conduction techniques in mild carpal tunnel syndrome. Arquivos de Neuro-Psiquiatria, 60(4), 923-927.

[45] Zeidman L, Singh S and Pandey D. (2014). Higher Diagnostic Yield with the Combined Sensory Index in Mild Carpal Tunnel Syndrome. Journal of Clinical Neuromuscular Disease, 15(4), 143-146.

[46] Eftekharsadat, Bina et al. (2014). Validity of current electrodiagnostic techniques in the diagnosis of carpal tunnel syndrome. Medical journal of the Islamic Republic of Iran, 2845.

[47] Borire AA, Hughes AR, Lueck CJ, Colebatch JG and Krishnan AV. (2016). Sonographic differences in carpal tunnel syndrome with normal and abnormal nerve conduction studies. Journal of Clinical Neuroscience, 34, 77-80.

[48] Kerasnoudis A. (2013). Re: "Ultrasonography for Diagnosing Carpal Tunnel Syndrome: A Meta-Analysis of Diagnostic Test Accuracy." Ultrasound in Medicine \& Biology, 39(6), 1129.

[49] Ha DS, Kim HS, Kim JM and Lee KH. (2017). The Correlation Between Electrodiagnostic Results and Ultrasonographic Findings in the Severity of Carpal Tunnel Syndrome in Females. Annals of Rehabilitation Medicine, 41(4), 595.

[50] Roghani RS, Holisaz MT, Norouzi AAS, Delbari A, Gohari F, Lokk J, et al. (2018). Sensitivity of high-resolution ultrasonography in clinically diagnosed carpal tunnel syndrome patients with hand pain and normal nerve conduction studies. Journal of Pain Research, 11, 1319-25.

[51] Sernik R, Abicalaf C, Pimentel B, Braga-Baiak A, Braga L and Cerri G. (2007). Ultrasound features of carpal tunnel syndrome: a prospective case-control study. Skeletal Radiology, 37(1), 49-53. 
[52] Peng F, Zhang L, Rehemutula A, Yu C, Wang T and Chen L. (2015). Does the ratio of the carpal tunnel inlet and outlet cross-sectional areas in the median nerve reflect carpal tunnel syndrome severity? Neural Regeneration Research, 10(7), 1172.

[53] Klauser A, Halpern E, De Zordo T, Feuchtner G, Arora R, Gruber J et al. (2009). Carpal Tunnel Syndrome Assessment with US: Value of Additional Cross-sectional Area Measurements of the Median Nerve in Patients versus Healthy Volunteers. Radiology, 250(1), 171-177.

[54] Hobson-Webb LD, Massey JM, Juel VC and Sanders DB. (2008).The ultrasonographic wrist-to-forearm median nerve area ratio in carpal tunnel syndrome. Clinical Neurophysiology, 119(6), 1353-7.

[55] Wang W, Hanson T and Fowler J. (2019). A Comparison of 6 Diagnostic Tests for Carpal Tunnel Syndrome Using Latent Class Analysis. HAND, 155894471983370.

[56] Roghani RS, Hashemi SE, Holisaz MT, Gohari F, Delbari A and Lokk J. (2018). The diagnostic accuracy of median nerve ultrasonography in elderly patients with carpal tunnel syndrome: sensitivity and specificity assessment. Clinical Interventions in Aging, 13, 1953-62.

\section{How to cite this article}

Aziz N. (2020). Diagnosis of carpal tunnel syndrome in perspective of clinical features, neurophysiological studies and high resolution ultrasound. World Journal of Advanced Research and Reviews, 6(3), 86-96. 